\title{
Studies on bismuth carboxylates—synthesis and characterization of a new structural form of bismuth(III) dipicolinate
}

\author{
O ANJANEYULU and K C KUMARA SWAMY* \\ School of Chemistry, University of Hyderabad, Hyderabad 500046, India \\ e-mail:kckssc@uohyd.ernet.in,kckssc@yahoo.com
}

\begin{abstract}
Synthesis and $\mathrm{X}$-ray structure of a new bismuth dipicolinate cooordination polymer, $\{[\mathrm{Bi}((2,6-$ $\left.\left.\left.\left.\mathrm{O}_{2} \mathrm{C}\right)_{2} \mathrm{C}_{5} \mathrm{H}_{3} \mathrm{~N}\right)\left(\left(2-\mathrm{HO}_{2} \mathrm{C}-6-\mathrm{O}_{2} \mathrm{C}\right) \mathrm{C}_{5} \mathrm{H}_{3} \mathrm{~N}\right)\left(\mathrm{H}_{2} \mathrm{O}\right)\right]_{2} .5 \mathrm{H}_{2} \mathrm{O}\right\}_{n}(7)$ are presented. Compound 7 has dimeric units with a $\mathrm{Bi}_{2} \mathrm{O}_{2}$ skeleton that are linked by additional weak $\mathrm{Bi}-\mathrm{O}$ interactions leading to a polymeric structure. The overall coordination number at bismuth is 9 [two $\mathrm{Bi}-\mathrm{N}$ and seven $\mathrm{Bi}-\mathrm{O}$ bonds]. New routes to a second crystalline modification $\left(\mathbf{4}^{\prime}\right)$ of the previously reported coordination polymer, bismuth tris(picolinate), $[\mathrm{Bi}(2-$ $\left.\left.\mathrm{O}_{2} \mathrm{C}-\mathrm{C}_{5} \mathrm{H}_{4} \mathrm{~N}\right)_{3}\right]_{n}(\mathbf{4})$, are described; bond parameters in the two crystalline forms $\left(\mathbf{4}\right.$ and $\left.\mathbf{4}^{\prime}\right)$ are compared. In both the compounds $\mathbf{4}^{\prime}$ and $\mathbf{7}$, bismuth has a distorted tricapped trigonal prismatic geometry.
\end{abstract}

Keywords. Bismuth; picolinic acid; dipicolinic acid; X-ray crystal structure; coordination polymer; carboxylate.

\section{Introduction}

A large number of bismuth compounds are clinically active against Helicobacter pylori and other gastrointestinal disorders. ${ }^{1-2}$ Prominent among these are bismuth subsalicylate (trade name Pepto-Bismol), colloidal bismuth subcitrate (CBS, trade name De-Nol) and ranitidine bismuth citrate (trade name Tritec). All these compounds are bismuth(III) carboxylates. Antimony also belongs to the same group, but clinically the most important compounds are of +5 oxidation state; these include sodium stibogluconate (trade name Pentostam) and meglumine antimonite (trade name Glucantime). The biological activity of these compounds, however, is assumed to involve the initial reduction of $\mathrm{Sb}(\mathrm{V})$ to $\mathrm{Sb}(\mathrm{III})$. Details on the structures of these compounds are still elusive, although in the case of bismuth, reasonable models like $\left[\mathrm{Bi}_{38} \mathrm{O}_{44}(\mathrm{Hsal})_{26}\left(\mathrm{Me}_{2} \mathrm{CO}\right)_{16}\left(\mathrm{H}_{2} \mathrm{O}\right)_{2}\right] \cdot\left(\mathrm{Me}_{2} \mathrm{CO}\right)_{4}$ and $\left[\mathrm{Bi}_{9} \mathrm{O}_{7}(\mathrm{Hsal})_{13}\left(\mathrm{Me}_{2} \mathrm{CO}\right)_{5}\right] \cdot\left(\mathrm{Me}_{2} \mathrm{CO}\right)_{1.5}$ are available (figure 1). ${ }^{3}$ Many of the structurally characterized bismuth subcitrates have the core, $\left[\mathrm{Bi}_{6} \mathrm{O}_{4}(\mathrm{OH})_{4}\right]^{6+}$. Structural studies on antimony(III) carboxylates are rather limited when compared to those on bismuth. ${ }^{4}$ However, there are a number of structurally characterized

*For correspondence
$\mathrm{Sb}(\mathrm{V})$ carboxylates/phosphinates including those from our research group (e.g., 1-3). ${ }^{5}$ We have embarked on a plan to extend this chemistry in the context of pharmaceutically active bismuth and antimony carboxylates. ${ }^{6}$ In this context, we have chosen the biologically compatible picolinic and dipicolinic acids as carboxylic acid

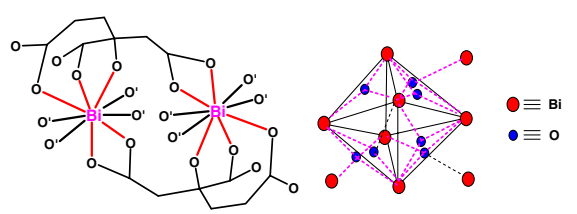

(a)

(b)

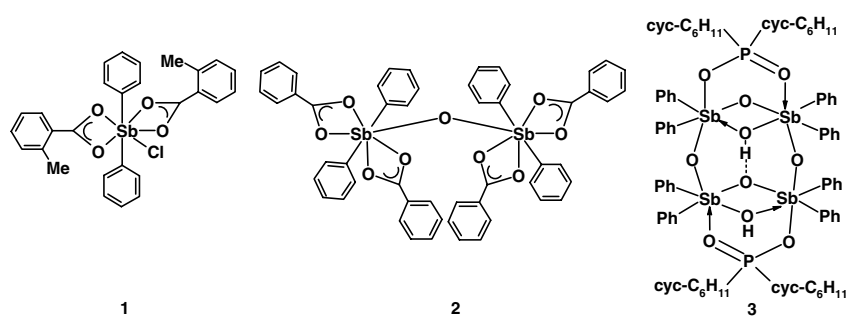

Figure 1. (a) Dinuclear $\left.\mathrm{Bi}(\mathrm{cit})_{2} \mathrm{Bi}\right]^{2-}$ subunit normally found in bismuth citrate compounds; $\mathrm{O}^{\prime}$ represents oxygen atom from citrate or water molecule. The terminal ' $\mathrm{O}$ ' atoms of the citrate group are further connected to form the coordination polymer chain. (b) $\mathrm{Bi}_{9} \mathrm{O}_{7}$ core structure in $\left[\mathrm{Bi}_{9} \mathrm{O}_{7}(\mathrm{Hsal})_{13}\left(\mathrm{Me}_{2} \mathrm{CO}\right)_{5}\right] \cdot\left(\mathrm{Me}_{2} \mathrm{CO}\right)_{1.5}$. 
sources. In this short paper, we discuss some of our findings on bismuth(III) picolinate and report a new structural form for bismuth bis(dipicolinate).

\section{Experimental}

Chemicals were procured from Aldrich or from local manufacturers. Infrared spectra were recorded on a JASCO FT/IR 5300 FT-IR spectrometer. Melting points were determined by using a local hot-stage melting point apparatus and are uncorrected. Microanalyses were performed using a Thermo Finnigan EA1112 analyzer. Thermogravimetric analysis (TGA) was carried out on a Netzsch STA 409 Pc TG-DTA instrument from 30 to $500^{\circ} \mathrm{C}$ with a scanning rate of $10 \mathrm{deg} / \mathrm{min}$. under nitrogen flow.

Compounds 4-6 have been reported by us recently. ${ }^{6}$ The crystalline polymorph $4^{\prime}$ was prepared by the 0.5:0.5:3 stoichiometric reaction of bismuth nitrate pentahydrate, gadolinium nitrate pentahydrate and picolinic acid; this is a much simpler route for this polymorph than that available in the literature. ${ }^{7}$ There was no significant change in the IR spectrum or the melting behaviour between 4 and $\mathbf{4}^{\prime}$.

\subsection{Reactions using ammonium bismuth citrate with pyridinecarboxylic acids}

2.1a Reaction with picolinic acid: Ammonium bismuth citrate (mol.wt. taken as $1875 ; 0.100 \mathrm{~g}$, $0.053 \mathrm{mmol})$ and picolinic acid $(0.039 \mathrm{~g}, 0.318 \mathrm{mmol})$ were dissolved in water $(10 \mathrm{~mL})$ at $25^{\circ} \mathrm{C}$. This led to immediate precipitation of insoluble microcrystalline compound that corresponded to $\left[\mathrm{Bi}\left(2-\mathrm{O}_{2} \mathrm{C}-\mathrm{C}_{5} \mathrm{H}_{4} \mathrm{~N}\right)_{3}\right]_{\mathrm{n}}$. Yield $0.020 \mathrm{~g}$ (65\% based on bismuth). Mp: $>320^{\circ} \mathrm{C}$. IR (KBr pellet): 3204(w), 3074(w), 1651(s), 1591(s), 1568(m), 1460(w), 1332(s), 1290(s), 1238(m), 1161(s), 1089(m), 1047(s), 1010(w), 835(s), 763(s), 694(s), 634(m) $\mathrm{cm}^{-1}$.

2.1b Reaction with dipicolinic acid - Synthesis of $\quad\left\{\left[\mathrm{Bi}\left(\left(2,6-\mathrm{O}_{2} \mathrm{C}\right)_{2} \mathrm{C}_{5} \mathrm{H}_{3} \mathrm{~N}\right)\left(\left(2-\mathrm{HO}_{2} \mathrm{C}-6-\mathrm{O}_{2} \mathrm{C}\right) \mathrm{C}_{5} \mathrm{H}_{3} \mathrm{~N}\right)\right.\right.$ $\left.\left.\left(\mathrm{H}_{2} \mathrm{O}\right)\right]_{2} \cdot 5 \mathrm{H}_{2} \mathrm{O}\right\}_{\mathrm{n}}$ (7): Ammonium bismuth citrate (mol. wt. taken as $1875 ; 0.100 \mathrm{~g}, 0.053 \mathrm{mmol}$ ) was dissolved in water $(10 \mathrm{~mL})$, and dipicolinic acid $(0.053 \mathrm{~g}, 0.318 \mathrm{mmol})$ was added to the solution at room temperature. The resulting clear solution was allowed to evaporate at room temperature to obtain colourless crystals of 7 over a period of 5-6 days. Yield $0.045 \mathrm{~g}$ (70\% based on Bi). Mp: $>320^{\circ} \mathrm{C}$. IR (KBr pellet): 3393(w), 3169(w), 3082(w), 1641(s), 1612(w), 1581(m), 1425(s), 1377(s), 1269(m), 1178(s), 1078(s), 1018(s), 916(s), 767(s), 727(s), 665(s) $\mathrm{cm}^{-1}$. Anal. Calc. For $\mathrm{C}_{28} \mathrm{H}_{18} \mathrm{~N}_{4} \mathrm{O}_{23} \mathrm{Bi}_{2}: \mathrm{C}, 27.87 ; \mathrm{H}, 2.33$; N, 4.64\%. Found: C, 27.85; H, 2.36; N, 4.71. This compound was also obtained (X-ray evidence) in $65 \%$ yield when a mixture of $\mathrm{Bi}\left(\mathrm{NO}_{3}\right)_{3}$ and $\mathrm{Gd}\left(\mathrm{NO}_{3}\right)_{3}$ was treated with dipicolinic acid in aqueous medium at reflux temperature and crystallizing the compound after cooling the solution to $\mathrm{ca} 25^{\circ} \mathrm{C}$.

2.1c Reaction with quninaldic acid: In this case, a well-defined compound could not be obtained.

\section{$2.2 X$-ray structural analysis of $4^{\prime}$ and 7}

X-ray data were collected on a Bruker AXS SMART or Oxford diffractometer using Mo-K $\mathrm{K}_{\alpha}(\lambda=0.71073 \AA)$ radiation. The structures were solved by direct methods. ${ }^{8}$ In the case of $\mathbf{4}^{\prime}$, all atoms except the bismuth were refined isotropically. Although a solution could be found in the space group $P 2_{1} / \mathrm{m}$ also, there were too many short contacts among different oxygen atoms with a large number (13) of $\mathrm{Bi}-\mathrm{O}$ contacts and hence was not considered; this could also indicate a disordered structure. For 7, all the non-hydrogen atoms were refined anisotropically; hydrogen atoms were located by Fourier Difference maps and then were allowed ride on the respective non-hydrogen atom as appropriate.

2.2a Crystal data: Compound 4': $\mathrm{C}_{18} \mathrm{H}_{12} \mathrm{BiN}_{3} \mathrm{O}_{6}$, $M=575.29$, Monoclinic, space group $P 2_{1}, a=$ 11.068(1), $b=7.743(1), c=11.277(1) \AA, \beta=$ 116.123(9), $V=867.73(10) \AA^{3}, Z=2, \rho=$ $2.202 \mathrm{gcm}^{-3}, \mathrm{~F}(000)=544, \mu=10.203 \mathrm{~mm}^{-1}$, Data/restraints/parameters: 2655/28/118. Flack parameter $0.00(1), S$ (all data) $=1.100$, R indices $(\mathrm{I}>2 \sigma(\mathrm{I}))$ : $\mathrm{R} 1=0.0273$, wR2 (all data) $=0.0744$. Max. $/ \mathrm{min}$. residual electron density $\left(\mathrm{e} \AA^{-3}\right) 1.034 /-1.069$. Literature $^{7}$ values of crystal dimensions $(a, b, c, \beta)$ are: $11.010(1), 7.749(1), 11.227(1) \AA$ and $116.361(7)^{\circ}$. Further details are available with the authors.

Compound 7: $\mathrm{C}_{28} \mathrm{H}_{28} \mathrm{Bi}_{2} \mathrm{~N}_{4} \mathrm{O}_{23}, M=1206.50$, Triclinic, space group $P_{-}-1, a=7.1268(5), b=$ 11.0010(8), $c=12.1409(7) \AA, \alpha=111.841(6), \beta=$ 96.555(5), $\gamma=90.320(6) . V=876.58(10) \AA^{3}, Z=1$, $\rho=2.286 \mathrm{gcm}^{-3}, \mathrm{~F}(000)=574, \mu=10.126 \mathrm{~mm}^{-1}$, Data/restraints/parameters: 2991/11/283, $S$ (all data) $=$ $0.986, \mathrm{R}$ indices $(\mathrm{I}>2 \sigma(\mathrm{I})): \mathrm{R} 1=0.0239$, wR2 (all 

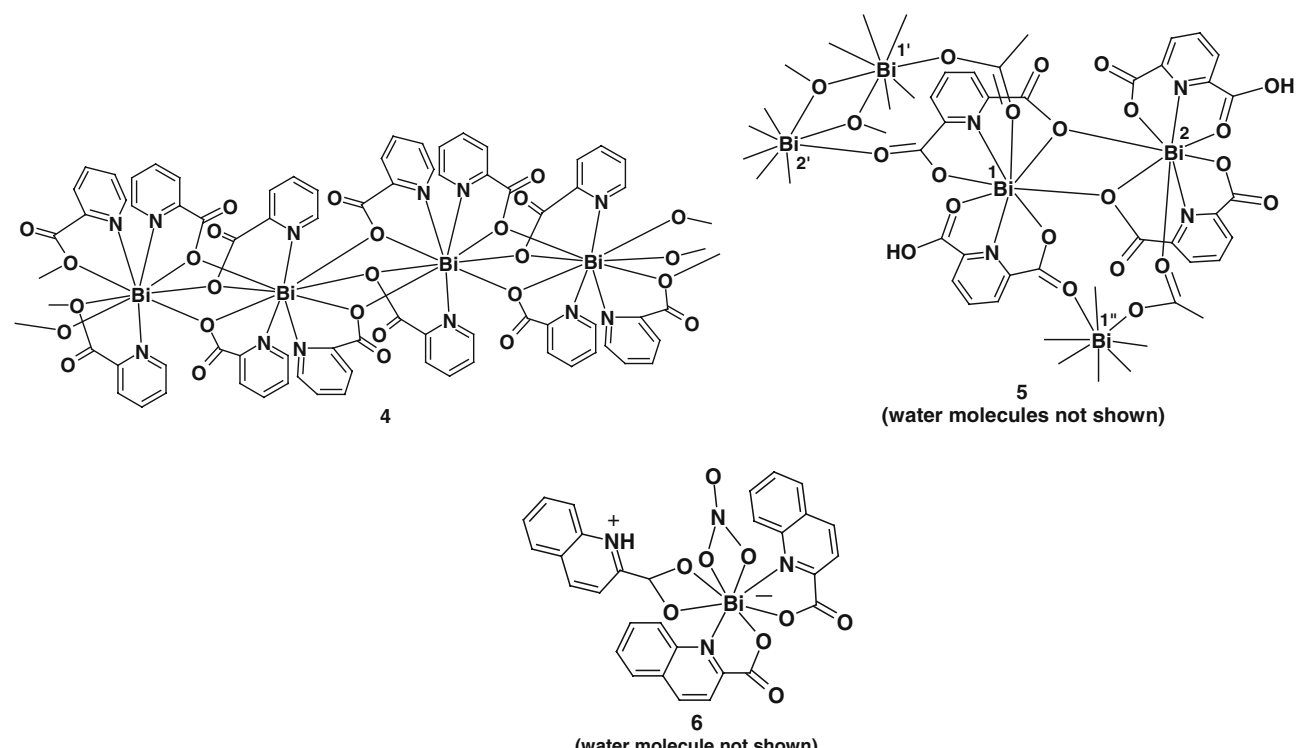

data $)=0.0527$. Max./min. residual electron density $\left(\mathrm{e}^{-3}\right) 1.088 /-1.071$.

Further details as CIF files on $\mathbf{7}$ are available from the Cambridge Crystallographic Data Centre, 12 Union Road, Cambridge CB2 1EZ, UK on request, quoting the deposition number CCDC 759762.

\section{Results and discussion}

On the basis of Pearson's hard-soft acid-base theory, $\mathrm{Bi}(\mathrm{III})$ can be considered to be a borderline acid, but it does bind fairly strongly with multidentate ligands possessing $\mathrm{O}$ and $\mathrm{N}$ donor atoms. Thus, it may be expected that anions of aminopolycarboxylic and polyaminopolycarboxylic acids form stable complexes with $\mathrm{Bi}(\mathrm{III})$. Several structural studies on iminodiacetic and nitrilotriacetic acid derivatives have been reported but those on picolinates are scanty. Since $\mathrm{Bi}(\mathrm{III})$ ion is large, we can naturally expect coordination numbers of greater than six in most of its complexes. In our recent study, we have described the synthesis and structures of compounds $[\mathrm{Bi}(2-$ $\left.\left.\mathrm{O}_{2} \mathrm{C}-\mathrm{C}_{5} \mathrm{H}_{4} \mathrm{~N}\right)_{3}\right]_{\mathrm{n}}$ (4; space group $\left.P 2_{1} / \mathrm{n}\right), \quad\{\mathrm{Bi}[(2,6-$ $\left.\left.\left.\left.\mathrm{O}_{2} \mathrm{C}\right)_{2} \mathrm{C}_{5} \mathrm{H}_{3} \mathrm{~N}\right)\right]\left[\left(2-\mathrm{HO}_{2} \mathrm{C}-6-\mathrm{O}_{2} \mathrm{C}\right) \mathrm{C}_{5} \mathrm{H}_{3} \mathrm{~N}\right] \cdot \mathrm{H}_{2} \mathrm{O}\right\}_{\mathrm{n}}$ and $\mathrm{Bi}\left(\mathrm{O}_{2} \mathrm{CC}_{9} \mathrm{H}_{6} \mathrm{~N}\right)_{2}\left(\mathrm{O}_{3} \mathrm{~N}\right)\left(\mathrm{O}_{2} \mathrm{CC}_{9} \mathrm{H}_{6} \mathrm{NH}\right) .2 \mathrm{H}_{2} \mathrm{O}(\mathbf{6}) ;{ }^{6}$ while $\mathbf{4}$ and $\mathbf{5}$ are coordination polymers, compound $\mathbf{6}$ is a monomer. All of these were obtained by the reaction of the readily accessible bismuth nitrate and the corresponding pyridine carboxylic acids. In view of another recent report that described $\left[\mathrm{Bi}\left(2-\mathrm{O}_{2} \mathrm{C}-\mathrm{C}_{5} \mathrm{H}_{4} \mathrm{~N}\right)_{3}\right]_{\mathrm{n}}$ in another polymorphic form $\mathbf{4}^{\prime}$ (space group $P 2_{1}$ ), we prepared this compound by treating ammonium bismuth citrate with picolinic acid, but in this case the reaction was too fast and the product was obtained only as an insoluble microcrystalline precipitate. However, while attempting to isolate a bimetallic complex using $\mathrm{Gd}\left(\mathrm{NO}_{3}\right)_{3} 5 \mathrm{H}_{2} \mathrm{O}, \mathrm{Bi}\left(\mathrm{NO}_{3}\right)_{3} .5 \mathrm{H}_{2} \mathrm{O}$ and picolinic acid, we obtained crystalline $\left[\mathrm{Bi}\left(2-\mathrm{O}_{2} \mathrm{C}-\mathrm{C}_{5} \mathrm{H}_{4} \mathrm{~N}\right)_{3}\right]_{\mathrm{n}}$ in the second polymorphic form $\mathbf{4}^{\prime}$ (figure 2 ). The bond distances in the two crystalline modifications are shown in table 1 along with that reported by Callens et $a .^{7}$ There are moderate differences in the bond distancesin the two modifications $\mathbf{4}$ and $\mathbf{4}^{\prime}$. However, the main point arising out of the present study is that even in the modification $\mathbf{4}^{\prime}$, the coordination number of bismuth is nine and the geometry can be described as tricapped trigonal prism. There are three $\mathrm{Bi}-\mathrm{O}$ covalent bonds, three $\mathrm{Bi}-\mathrm{N}$ coordinate covalent bonds and three $\mathrm{Bi}-\mathrm{O}$ coordinate covalent bonds (with one of them weaker than the other two). Coordination number of only 8 is ascribed to $4^{\prime}$ in the literature. $^{7}$

The reaction of ammonium bismuth citrate with dipicolinic acid in water leads to compound $\quad\left\{\left[\mathrm{Bi}\left(\left(2,6-\mathrm{O}_{2} \mathrm{C}\right)_{2} \mathrm{C}_{5} \mathrm{H}_{3} \mathrm{~N}\right)\left(\left(2-\mathrm{HO}_{2} \mathrm{C}-6-\right.\right.\right.\right.$ $\left.\left.\left.\left.\mathrm{O}_{2} \mathrm{C}\right) \mathrm{C}_{5} \mathrm{H}_{3} \mathrm{~N}\right)\left(\mathrm{H}_{2} \mathrm{O}\right)\right]_{2} .5 \mathrm{H}_{2} \mathrm{O}\right\}_{\mathrm{n}}$ (7) which is different from $\left\{\mathrm{Bi}\left[\left(2,6-\mathrm{O}_{2} \mathrm{C}\right)_{2} \mathrm{C}_{5} \mathrm{H}_{3} \mathrm{~N}\right)\right]\left[\left(2-\mathrm{HO}_{2} \mathrm{C}-6-\right.\right.$ $\left.\left.\left.\mathrm{O}_{2} \mathrm{C}\right) \mathrm{C}_{5} \mathrm{H}_{3} \mathrm{~N}\right] \cdot \mathrm{H}_{2} \mathrm{O}\right\}_{\mathrm{n}}$ (5) obtained by us earlier using bismuth nitrate pentahydrate and dipicolinic acid. ${ }^{6}$ 

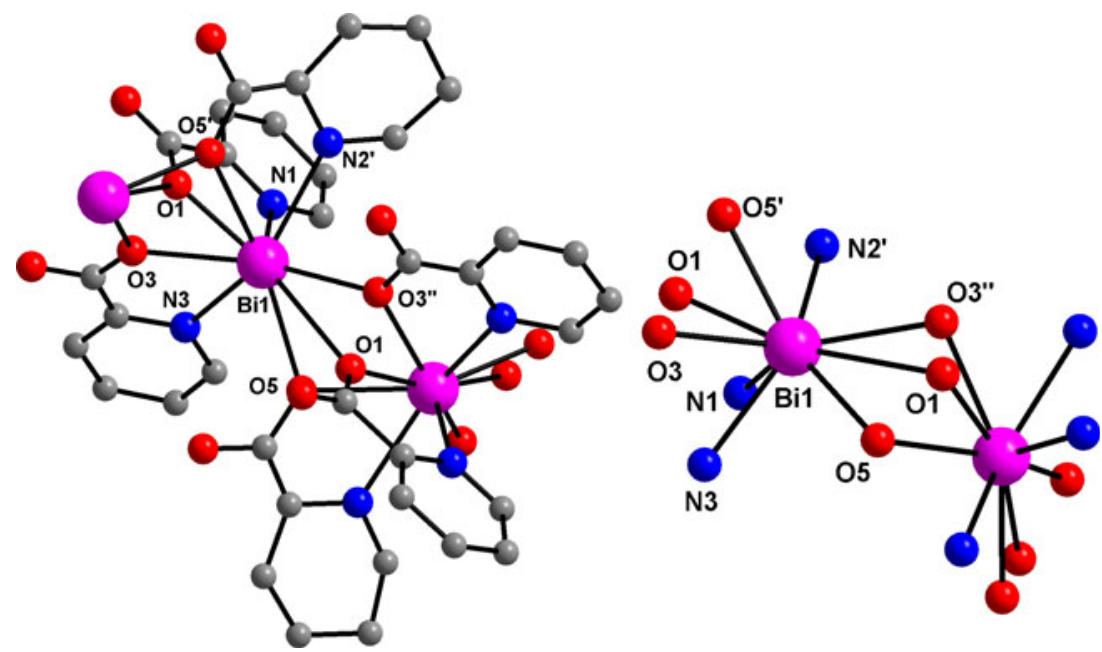

Figure 2. Molecular structure of $\mathbf{4}^{\prime}$. Only the bismuth and the corresponding coordinated atoms are shown. Symmetry codes (i) $-\mathrm{x},-0.5+\mathrm{y}, 2-\mathrm{z}$; (ii) $-\mathrm{x}$, $0.5+\mathrm{y}, 2-\mathrm{z}$.

Compound 7 was also obtained when a mixture of bismuth nitrate pentahydrate and gadolinium nitrate pentahydrate were treated with dipicolinic acid. In the

Table 1. Comparison of the bond distances in the two polymorphs 4 and $\mathbf{4}^{\prime}(\AA)^{\mathrm{a}}$.

\begin{tabular}{lcc}
\hline Polymorph & $\mathbf{4}$ & $\mathbf{4}^{\prime}$ \\
Space group & $P 2_{1} / \mathrm{n}$ & $P 2_{1}^{\mathrm{b}, \mathrm{c}}$ \\
$\mathrm{Bi}-\mathrm{N}$ & $2.425(5)$ & $2.438(8)$ \\
& $2.588(5)$ & $2.571(6)$ \\
$\mathrm{Bi}-\mathrm{O}$ & $2.627(5)$ & $2.620(7)$ \\
& $2.314(4)$ & $2.242(7)$ \\
& $2.425(4)$ & $2.533(7)$ \\
& $2.446(4)$ & $2.559(7)$ \\
& $2.484(4)$ & $2.563(7)$ \\
& $2.636(4)$ & $2.614(7)$ \\
& $2.935(4)$ & $2.987(9)$
\end{tabular}

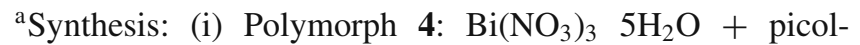
inic acid; (ii) polymorph $4^{\prime}: \mathrm{Bi}\left(\mathrm{NO}_{3}\right)_{3} 5 \mathrm{H}_{2} \mathrm{O}+\mathrm{Gd}\left(\mathrm{NO}_{3}\right)_{3}$ $5 \mathrm{H}_{2} \mathrm{O}+$ picolinic acid (this work) or $\mathrm{Bi}(0)+$ pyridine + acetic acid $+t-\mathrm{BuOOH}+$ picolinic acid $\left(\text { ref. }^{7}\right)^{+}$.

${ }^{\mathrm{b}}$ Refinement of thermal parameters except for bismuth could be done only isotropically. In the cif data available in the CCDC database corresponding to ref. ${ }^{7}$ also, only isotropic refinement is reported. In our case, although the structure could be solved in the higher symmetry space group $P 2_{1} / \mathrm{m}$, there were too many short $\mathrm{O}$...O contacts and a rather questionable coordination number of 13 on bismuth. Hence this space group was not considered further.

${ }^{\mathrm{c}}$ Corresponding distances (except the last entry) as reported in ref. ${ }^{7}: 2.430$ (9), 2.588 (7), 2.633(7), 2.296 (6), 2.473(6), 2.531(6), 2.574(6) and 2.648(6) ̊. latter case, it is likely that competition (albeit weaker) for the ligand by gadolinium resulted in the formation of 7 (rather than 5). A glance at the formula of 5 and 7 would indicate that there is only a difference in the number of molecules of water, but structurally, the two compounds are quite different. In $\mathbf{5}$, the water molecules are not coordinated to bismuth while in 7, each bismuth is coordinated to a water molecule (figures 3-5), thus leaving one of the carboxylate oxygen atoms for hydrogen bonding interactions. The structural drawings for the dimeric unit in $\mathbf{7}$ are given in figure 4; the supramolecular structure leading to the coordination polymer is shown in figure 5 . Bond distances in $\mathbf{5}$ and $\mathbf{7}$ are compiled in table 2 . As discussed in our previous paper, ${ }^{6}$ there are two types of bismuth environments in $\mathbf{5}$. Also, there are both dimeric $\left[\mathrm{Bi}_{2} \mathrm{O}_{2}\right]$ and trimeric [BiOCOBiOBiOCO] moieties in the overall structure. By contrast, in 7, only one type of bismuth environment with a $\mathrm{Bi}_{2} \mathrm{O}_{2}$ skeleton is seen; these units are linked further to form an extended tetranuclear cage (cf. figure 5). The Bi1-O6" and Bi1-O9"' distances involving the bridging oxygen atom of dimeric unit and the coordinated water are much longer than the other $\mathrm{Bi}-\mathrm{O}$ distances in 7 , as expected. The $\mathrm{Bi}-\mathrm{N}$ distances in the two compounds are in a similar range. Since bismuth is trivalent in both the compounds, between the two dipicolinates per bismuth, one free carboxylic acid-OH residue is still present in each. Although there are two distinct bismuth atoms in the asymmetric unit of $\mathbf{5}$, both exhibit eight coordination 


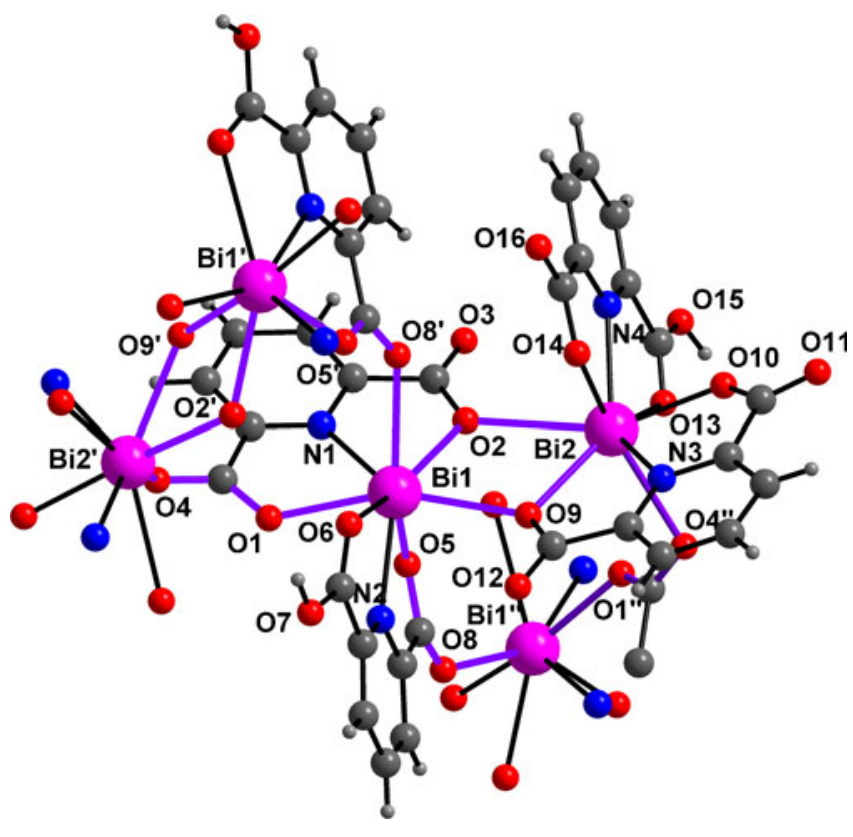

Figure 3. Molecular structure with atoms bound to bismuth being labelled. See ref. ${ }^{6}$ for labelling on all the atoms. Symmetry operators: (i) $-\mathrm{x}+1, \mathrm{y}+1 / 2,-\mathrm{z}+1 / 2$; (ii) $-\mathrm{x}+1$, $\mathrm{y}-1 / 2,-\mathrm{z}+1 / 2$.

with dodecahedral geometry at bismuth. However in 7, the coordination number at bismuth is nine and the geometry can be described as distorted tricapped trigonal prism (cf. figure 4). In both the compounds, the supramolecular structure can be construed to have resulted in coordination polymers.

There are several hydrogen bonding interactions in both 5 and 7. While the water molecules are not coordinated to bismuth in $\mathbf{5}$, both coordinated and noncoordinated water molecules are found in 7. Also, there are more water molecules per bismuth in 7 which contribute to the difference in the two structures. Two water molecules in the asymmetric unit of 5 [i.e., one per bismuth] form a 'dimer' but are involved in hydrogen bonding to other atoms also. The corresponding $\mathrm{O}$...O distances are (i) $\mathrm{O}(15) . . \mathrm{O}(17)$ [symm: $\mathrm{x}$, $\mathrm{y}-1, \mathrm{z}]$ 2.520(10), (ii) $\mathrm{O}(17) \ldots \mathrm{O}(18) 2.714(17)$, (iii) $\mathrm{O}(18) \ldots \mathrm{O}(16)$ 2.792(9) and (iv) $\mathrm{O}(18) \ldots \mathrm{O}(13)$ [symm: $\mathrm{x}, 1+\mathrm{y}, \mathrm{z}] 3.385(11) \AA .{ }^{6}$ In 7 , both the hydrogen atoms of the coordinated water are involved in hydrogen bonding, one to an oxygen atom of carboxylate moiety and the other to the oxygen of a non-coordinated water molecule. The relevant $\mathrm{O}$...O distances are (i) $\mathrm{O}(9) \ldots \mathrm{O}(5)$ [symm: $-\mathrm{x}, 1-\mathrm{y},-\mathrm{z}] 2.826(6)$ and (ii) $\mathrm{O}(9)$... O(10) 3.148(12) ̊.
It may be noted that the two forms $\mathbf{5}$ and 7, are prepared under slightly different conditions by using different precursors. Compound $\mathbf{5}$ is obtained under reflux conditions using bismuth nitrate because of the poor solubility of the nitrate. Compound 7 is formed at room temperature using the soluble ammonium bismuth citrate. We believe that the difference in temperature has resulted in the different structures and the use of a lower temperature to prepare 7 has led to a higher stoichiometry of water being retained in the lattice.

Iminodiacetic acid $\left[\mathrm{HN}\left(\mathrm{CH}_{2} \mathrm{COOH}\right)_{2}, \mathrm{H}_{2}\right.$ ida] with two carboxylic acid moieties and a coordinatively active nitrogen is similar to dipicolinic acid and hence it is worth comparing the structures involving the carboxylates anions of these. The complex $\mathrm{Bi}(\mathrm{Hida})(\mathrm{ida})(\mathbf{8})$ is also a coordination polymer, but with coordinated/or non-coordinated water molecules being absent. ${ }^{1 e, 9}$ The coordination number of bismuth is eight which is similar to that in 5, but different from that in $\mathbf{7}$. However, the structure is quite different from either $\mathbf{5}$ or $\mathbf{7}$. While the $\mathrm{ida}^{2-}$ forms 5-membered ring chelate rings through a nitrogen and two carboxylate anions, the $\mathrm{Hida}^{-}$part forms 4-membered $\mathrm{O}, \mathrm{O}$-chelate and participates in bridging; the nitrogen atom of the latter does not coordinate to bismuth (figure 6). ${ }^{10}$ This feature (when compared with that of $\mathbf{5}$ or $\mathbf{7}$ ) suggests that new structural types for bismuth iminodiacetates should be amenable for further studies. Work in this direction is in progress in our laboratory. ${ }^{11}$

\section{Summary}

By means of simple water mediated reactions, coordinatively polymeric pyridine carboxylates of bismuth have been synthesized and characterized. New routes to different structural forms for the bismuth picolinate $\left[\mathrm{Bi}\left(2-\mathrm{O}_{2} \mathrm{C}-\mathrm{C}_{5} \mathrm{H}_{4} \mathrm{~N}\right)_{3}\right]_{\mathrm{n}}$ are described. In the reaction using dipicolinic acid, it is shown that the use of bismuth nitrate or ammonium bismuth citrate as precursor leads to different structural entities. In the former case, a branched polymer 5 that features two types of bismuth environments each with eight coordination is obtained while in the latter case a different type of coordination polymer $\mathbf{7}$, in which a dimeric bismuth cage is connected via additional $\mathrm{Bi}-\mathrm{O}$ interaction to other similar units, is isolated and structurally characterized. The coordination number of bismuth in the latter compound is nine and the geometry is distorted tricapped trigonal prism. 

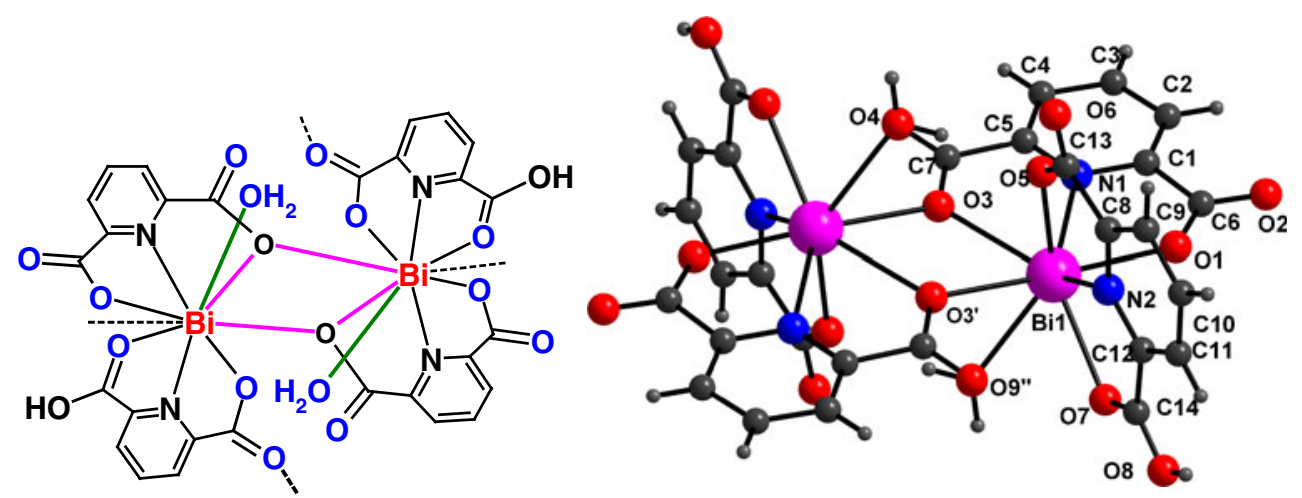

Figure 4. Molecular structure of the dimeric unit in 7. The ninth weaker coordination

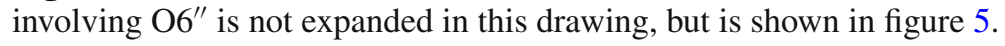
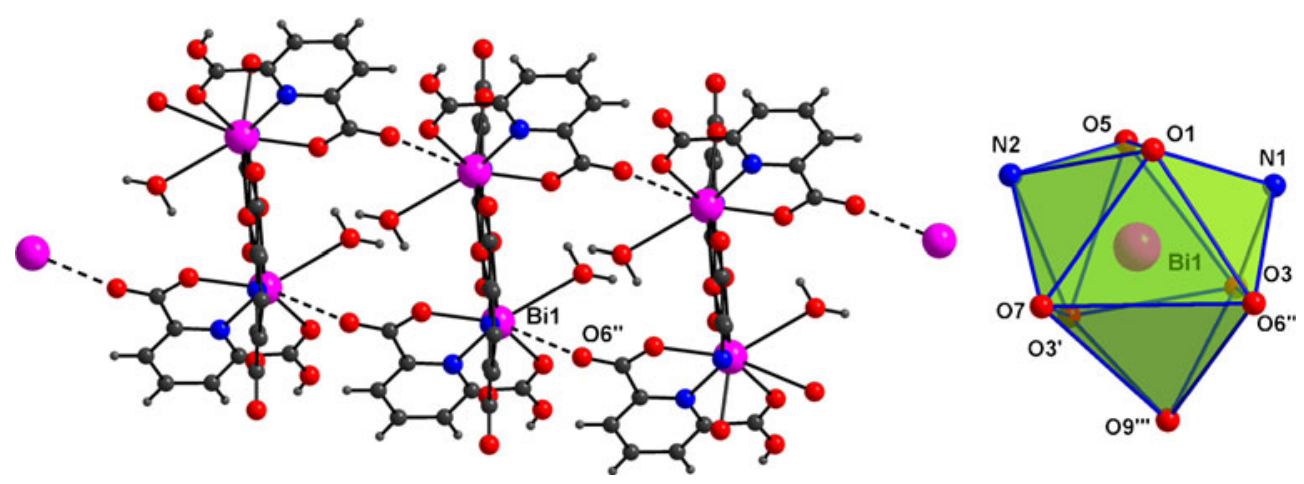

Figure 5. Left: Drawing showing the supramolecular motif via additional Bi...O interactions in 7. Right: Polyhedron showing the distorted tricapped trigonal prismatic geometry at bismuth. Symmetry codes: (i) $-\mathrm{x},-\mathrm{y},-\mathrm{z}$; (ii) $1+\mathrm{x}, \mathrm{y}, \mathrm{z}$; (iii) $\mathrm{x},-1+\mathrm{y}, \mathrm{z}$.

Table 2. Selected bond distances in $\mathbf{5}$ and $\mathbf{7}(\AA){ }^{\mathrm{a}, \mathrm{b}}$

\begin{tabular}{|c|c|c|c|c|c|}
\hline Compound & & 5 & & \multicolumn{2}{|c|}{7} \\
\hline Space group & & $P 2_{1} / \mathrm{c}$ & & \multicolumn{2}{|c|}{$P_{-}-1$} \\
\hline $\mathrm{Bi} 1-\mathrm{O} 1$ & $2.391(5)$ & $\mathrm{Bi} 2-\mathrm{O} 2$ & $2.763(4)$ & Bi1 O1 & $2.298(3)$ \\
\hline $\mathrm{Bi} 1-\mathrm{O} 2$ & $2.483(4)$ & $\mathrm{Bi2}-\mathrm{O} 4{ }^{\prime \prime}$ & $2.625(5)$ & Bi1 O3 & $2.670(4)$ \\
\hline Bi1-O5 & $2.230(5)$ & Bi2-O9 & $2.584(5)$ & Bi1 O3' & $2.583(3)$ \\
\hline Bi1-O6 & $2.793(5)$ & Bi2-O10 & $2.268(5)$ & Bi1 O5 & $2.281(4)$ \\
\hline $\mathrm{Bi}-\mathrm{O}^{\prime}$ & $2.635(5)$ & Bi2-O13 & $2.672(5)$ & Bi1 O7 & $2.530(4)$ \\
\hline Bi1-O9 & $2.524(5)$ & $\mathrm{Bi2}-\mathrm{O} 14$ & $2.239(5)$ & Bi1-O6" & $3.101(7)$ \\
\hline Bi1-N1 & $2.429(5)$ & Bi2-N3 & $2.398(5)$ & Bi1-O9'" & $2.891(11)$ \\
\hline Bi1-N2 & $2.478(5)$ & Bi2-N4 & $2.449(5)$ & Bi1 N1 & $2.475(4)$ \\
\hline & & & & Bi1 N2 & $2.417(4)$ \\
\hline
\end{tabular}

a Symmetry codes for compound 5: (i) $-\mathrm{x}+1, \mathrm{y}+1 / 2,-\mathrm{z}+1 / 2$; (ii) $-\mathrm{x}+1$, $y-1 / 2,-z+1 / 2$. Data from ref. ${ }^{6}$

${ }^{\mathrm{b}}$ Symmetry codes for compound 7: (i) $-\mathrm{x},-\mathrm{y},-\mathrm{z}$; (ii) $1+\mathrm{x}, \mathrm{y}, \mathrm{z}$; (iii) $\mathrm{x}$, $-1+\mathrm{y}, \mathrm{z}$. 


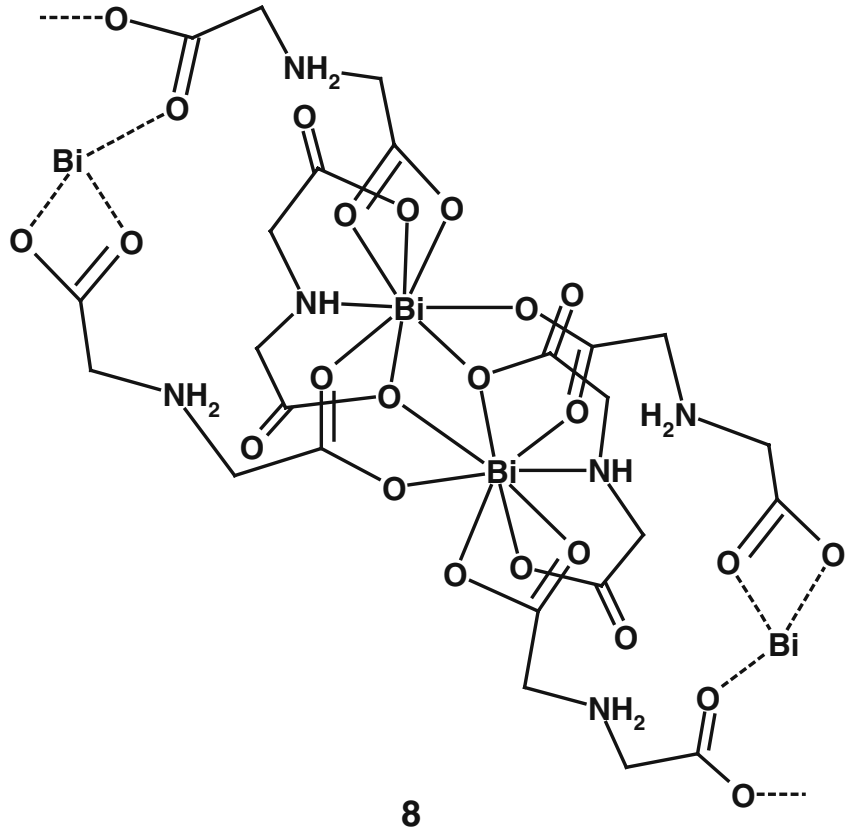

Figure 6. A structural drawing of $\mathrm{Bi}($ Hida)(ida) (8).

\section{Acknowledgements}

We thank the Department of Science and Technology (DST), New Delhi for funding and for setting up a Single Crystal X-ray Diffractometer Facility at the University of Hyderabad and for financial support; we also thank the University Grants Commission (UGC) (New Delhi) for equipment under the UPE program and Council for Scientific and Industrial Research (CSIR) for fellowship to OA.

\section{References}

1. Some useful reviews: (a) Guo Z and Sadler P J 1999 Angew. Chem. Int. Ed. 38 1512; (b) Briand G G and Burford N 1999 Chem. Rev. 99 2601; (c) Ge R and Sun H 2007 Acc. Chem. Res. 40 267; (d) Yang N and Sun H 2007 Coord. Chem. Rev. 251 2354; (e) Stavila V, Davidovich R L, Gulea A and Whitmire K H 2006 Coord. Chem. Rev. 2502782
2. Selected recent literature: (a) Thurston J H, Marlier E M and Whitmire K H 2002 Chem. Commun. 2834; (b) Andrews P C, Deacon G B, Jackson W R, Maguire M, Scott N M, Skelton B W and White A H 2002 J. Chem. Soc., Dalton Trans. 4634; (c) Thompson K H and Orvig C 2003 Science 300 936; (e) Briand G G, Burford N, Eelman M D, Aumeerally N, Chen L, Cameron T S and Robertson K N 2004 Inorg. Chem. 43 6495; (f) Yang N, Tanner J A, Wang Z, Huang J D, Zheng B J, Zhu N and Sun H 2007 Chem. Commun. 4413; (g) Andrews P C, Deacon G B, Ferrero R L, Junk P C, Kurrar A, Kumar I and MacLellan J G 2009 Dalton Trans. 6377

3. Andrews P C, Deacon G B, Forsyth C M, Junk P C, Kumar I and Maguire M 2006 Angew. Chem. Int. Ed. 45 5638

4. Machuča L, Dostál L, Jambor R, Handlî́r K, Jirásko R, Růžička A, Císařová I and Holećek J $2007 \mathrm{~J}$. Organomet. Chem. 6923969

5. (a) Said M A, Kumara Swamy K C, Poojary D M, Clearfield A, Veith M and Huch V 1996 Inorg. Chem. 35 3235; (b) Said M A, Kumara Swamy K C, Babu K and Nethaji M 1995 J. Chem. Soc. Dalton Trans. 2151; (c) Kumara Swamy K C, Said M A and Netaji M 1999 J. Chem. Crystallogr. 291103

6. Anjaneyulu O, Prasad T K and Kumara Swamy K C 2010 Dalton Trans. 391935

7. Callens E, Burton A J, White A J P and Barrett A G M 2008 Tetrahedron Lett. 493709

8. (a) Sheldrick G M 1996 SADABS, Siemens area detector absorption correction (University of Göttingen, Germany); (b) Sheldrick G M 1999 SHELXTL NT Crystal Structure Analysis Package, Bruker AXS, Analytical $X$-ray System, version 5.10 (WI, USA)

9. Davidovich R L, Gerasimenko A V, Logvinova V B 2001 Zh. Neorg. Khim. 46 1311; Russ. J. Inorg. Chem. 461178

10. The reason for the involvement of both the oxygen atoms of each of the carboxylate end of this ligand as well as the non-ligation of the nitrogen to bismuth is most likely due to the transfer of a carboxylic acid proton to the nitrogen rendering lone pair of electrons on the latter not available for donation. The cif file as deposited in the Cambridge database, gives only the coordinates of all the atoms and the final $\mathrm{R}$ values are not available.

11. We are also exploring the use of $\mathrm{BiCl}_{3}$ as the precursor, but the success has been rather limited: Srinivasa Rao A, Sunil Babu E, Kumara Swamy K C and Das S K 2010 Polyhedron 291706 